\title{
Notas sobre as contradições do processo de informatização social
}

-Escole Nacional de Saúde Pública - FIOCRUZ Rio de Janeiro.

\section{Maria Teresa de Oliveira*}

The electronic systems now in growing expansion almost all over the world creates areas of conflict on the different societies as well as on many cultural patterns. This article tries to establish the magnitude of these modifications.

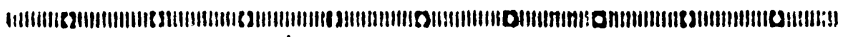

\section{CONSIDERAÇÕES GERAIS}

A disseminação dos recursos tecnológicos e das técnicas derivadas da informática é hoje um dos principais aspectos do processo de transformação das socie dades.

À medida que a sociedade automatizada se consolida, seus efeitos sobre diferentes áreas tornam-se mais visíveis. Nas áreas sociais, as ameaças sobre três séries de valores identidade humana, direitos de cada um e vida privada são sem dúvida as mais polêmicas, as que mais publicidade têm recebido e que produziram maiores conseqüências legais, sobretudo nos paises ditos centrais.

Privacidade

$\mathrm{O}$ direito de cada ser humano à vida privada ou "privacidade" foi definido pela primeira vez por Warren e Brandeis, em 1890, como sendo "o direito a ser deixado sozinho". Esta definição foi retomada pelo Dr. Willis Ware da Rand Corporation, Santa Monica, California. ${ }^{2}$ Oriundo da palavra inglesa "privacy", é valor que goza de larga au diência nas sociedades anglo-germânicas. Outros autores agregaram a esse conceito relativo à solidão, os direitos à intimidade, ao anonimato e a recusar-se a responder a interrogatórios. Posteriormente, com a in tervenção da automação, a definição ganhou amplitude, englobando notadamente: 1) o direito de determinar quando, como e em que medida as informações pessoais podem ser comunicadas e usadas por outros; 2) a proteção dos indivíduos contra danos resultantes da operação de sistemas de informação; e 3) a proteção dos indivíduos contra a coleta e a disseminação imprópria ou excessiva de dados pessoais.

A esses elementos costuma-se acrescentar os direitos ao trabalho, ao livre trânsito e à liberdade de culto, pensamento e expressão que, entre os direitos consagrados na Declaração Universal dos Direitos Humanos e no PactoInternacional Relativo aos Direitos Civis e Políticos, são 
vistos como os mais ameaçados, pelo menos potencialmente, pelos recursos dos instrumentos tecnológicos. Essas definições são suscitadas claramente pelas possibilidades do computador, que viabiliza a agregação de dados pessoais e, portanto, novas leituras desses dados antes dispersos em arquivos manuais. Os "rastros" que as pessoas deixam de sua existência podem ser hoje mais nítidos, graças ao uso dos recursos tecnológicos com que a moderna sociedade vem se dotando. ${ }^{6}$

A privacidade é uma questão que extrapola os simples limites individuais. Ela é a contradição do processo de expansão tecnológica, que estimula a coleta e organização de dados pessoais, sua acumulação e a concentração dessas informações nos bancos de dados públicos ou privados. Constituindo a base dessa contradição, estão as pessoas que prestam informaçðes sobre si mesmas, geralmente em dois casos: voluntariamente, em troca de serviços e benefícios securitários ou médico-hospitalares, por exemplo, e sob coerção, como é o caso dos censos. $\mathrm{Na}$ realidade, quem desejar obter qualquer documento tera que prestar informações sobre si mesmo: filiação, naturalidade, estado civil, etc. Além disso, em inúmeras outras circunstâncias, as pessoas são levadas a fornecer dados pessoais, como por exemplo ao hospedar-se em hotéis ou ao associar-se a cartões de crédito. Nesses casos em que não há coerção, se estabelece uma obrigatoriedade tácita dificilmente contestada. Ocorre, porém, que a pessoa perde o controle da informação, uma vez dada. Ela pode desde logo ser usada para fins diferentes daqueles para os quais foi explicitamente colhida. Pode também sofrer manipulações as mais variadas.

Quando as pessoas fornecem informações sobre si mesmas, não desejam, via de regra, nem esperam que estas sejam usadas para fins diferentes daqueles para os quais foram explicitamente prestadas. No entanto, é o que pode acontecer, pois, com o auxílio de inovaçōes tecnológicas diversas, é possivel identificar os participantes de qualquer manifestação política, bem como os informantes teoricamente anônimos de pesquisas. A pessoa que aceita responder a investigações sobre temas delicados, socialmente vulneráveis como o uso de tóxicos, por exemplo, não deseja provavelmente ser identificada. Mas é passível de sê-lo, através dos cruzamentos de variáveis. Do mesmo modo, quem presta informações sobre si mesmo ao se inscrever numa companhia de crédito pode não desejar passar a receber pelo correio folhetos de propaganda; nem a mulher que ao postular um emprego declara seu estado civil espera ser prejudicada pelo fato de ser casada; nem o cidadão citado em juízo deseja ter seu comportamento avaliado com a ajuda de informaçóes estocadas em bancos de dados. 
A expansão progressiva do movimento de coleta e organização de dados sobretudo pessoais é uma característica geral das sociedades modernas, nas quais o Estado é freqüentemente centralizador e autoritário, e as instâncias civis se apresentam segmentadas. Nessas sociedades, os governos e os organismos policiais lançam mão cada vez mais de instrumentos tecnológicos para identificar e controlar populações que proliferam em proporções espantosas. Não necessariamente pelas mesmas razões, mas em igual ritmo, a sociedade civil multiplica bancos de dados públicos e privados, instituições de pesquisa como bibliotecas e universidades, cadastros de diversos tipos, etc. Tanto os poderes públicos como as instituições privadas participam de um movimento de expansão no que concerne às informações: colhem-se dados sobre tudo e sobre todos. A matéria-prima desse movimento é a valiosa informação.

A informação é possivelmente o principal mecanismo de poder criado e utilizado pelo ser humano desde que os antepassados da nossa espécie encontraram a maneira de codificá-la e registrá-la através da representação gráfica de fonemas e idéias. A descoberta da informação registrada - a escrita - pode estar entre as primeir íssimas grandes invenções da Humanidade. Ela tem por finalidade básica a acumulação da memória social, a fim de que cada geração extinta possa transmitir às subseqüentes sua experiência e seu conhecimento. Contudo, ela abre também a possibilidade de manipulação dessas informações em benefício de certos grupos que, sonegando-as aos demais, asseguram seu monopólio, o qual favorece o exercício e o abuso do poder, já que o registro e a acumulação propiciam o cruzamento das informações, possibilitam a manipulação das mesmas e, desde logo, sua apropriação por determinados grupos, castas e mais tarde classes, em detrimento dos demais. Pode-se dizer que, em todos os tempos, os indivíduos letrados foram auxiliares preciosos e muitas vezes intérpretes dos que chegavam ao poder. A instrução foi, por outro lado, apanágio de instituiçбes poderosas, como o clero. A partir do século XIX, esse processo resultou no surgimento do analfabetismo que se tornou um indicador da divisão social do poder e da riqueza: basta pensar que as pessoas são hoje remuneradas em função de sua qualificação e, no fundo, o que se paga é a quantidade de informaçðes depositadas nos seus sistemas nervosos pelo aprendizado ${ }^{3}$.

A informação registrada tem, então, esta dupla característica: a de constituir a base da memória social e a de ser um fundamento do poder, cujo caminho garante e cujo exercício favorece.

No seio dos debates sobre a privacidade, a questão da adoção de um número único é uma pedra de toque. 
O número único é um identificador universal. Não é pois uma novidade, porquanto todas as sociedades possuem um ou vários tipos de identificadores. A inclusão do nome de solteira da mãe em documentos é um exemplo clássico de método para identificar pessoas. No passado, o acoplamento do nome do lugar de nascimento ao sobrenome foi um outro recurso usado comumente para os mesmos fins. São exemplos célebres deste procedimento: o de Leonardo da Vinci, cuja familia assim se chamava por ser originária da localidade da Vinci, perto de Florença, e o de Erasmo de Rotterdam. Atualmente, no Brasil, adotam-se os seguintes processos de identificação: ao nascer, a pessoa recebe um número que atesta o nascimento, ao atingir a maioridade recebe outros (carteira de identidade, título de eleitor), ao ingressar no mercado de trabalho outros ainda (o CIC, a carteira de trabalho), e assim por diante. Deste modo, ao longo de sua vida, a pessoa recebe vários números de identificação, o nome e o sobrenome já não sendo mais considerados identificadores suficientes devido à complexificação da sociedade. Cada um desses números é controlado por uma instância administrativa distinta. No caso da adoção de um número único, essa situação sofrerá uma alteração substancial, pois este número, atribuído à pessoa desde o nascimento, acompanha-la-á durante toda a vida. Por haver somente um para cada, permite a localização de informaçðes espalhadas e o seu rápido cruzamento. Assim sendo, o número único é potencialmente um instrumento de controle social praticamente total, viabilizando em muito a invasão da privacidade.

Existem muitas formas de controle social. Para efeitos de análise, podemos agrupá-las em duas grandes categorias que sintetizam as múltiplas variedades desse mecanismo de poder. Em uma delas estão os tipos de controle social que se processam "informalmente", através da interiorização pelo ser humano das regras do jogo social. Esta interiorização, inicialmente levada a cargo por diferentes instituições como a familia, a escola, a religião, será posteriormente assimilada à conduta da pessoa, transformando-a por sua vez em fiscal e transmissora das normas e regras da sociedade ou em sua contestadora. O controle social deste tipo é bastante sofisticado, e seu objetivo é, em última análise, transformar normas e técnicas de coerção em elementos constitutivos da personalidade. Esta categoria abrange o controle que é conhecido em ciências sociais por processo de socialização.

$\mathrm{Na}$ outra categoria estão os controles coercitivos, repressivos e normativos "formais", diretamente vinculados ao poder e exercidos pelos aparelhos do Estado, principalmente os político-policial e militar, o médico-hospitalar-previdenciário, o asilar e o jurídico. Também uma parte da socie-
Número Único

Controle Social 
dade civil deles se utiliza, como é o caso dos partidos políticos, das associações profissionais, como os sindicatos, e das empresas privadas.

Com estas reflexões, à guisa de pano de fundo, pode-se melhor pensar a questão das relações que se estabelecem entre o controle social e a informática.

\section{DA INFORMAÇÃO À INFORMÁTICA}

Num determinado nivel de análise, a informática é o aperfeiçoamento mais recente de uma extensa gama de aparelhos e técnicas transmissores e operadores de informações. $O$ adulto contemporâneo se defronta com elas cada vez mais no seu dia-a-dia. Os meios de comunicação de massa como o cinema, a imprensa e a televisão se encarregam de divulgar as inovaçoes tecnológicas, focalizando principalmente o computador, ora para enriquecer sua mitologia, ora para atacá-la.

Cinema O cinema já mostrou inúmeras vezes as inovações tecnológicas. O filme "2001 - Uma odisséia no espaço", de Stanley Kübrick, apresentou minuciosamente um arsenal de gadgets eletrônicos, incluindo computadores de grande porte. $O$ diretor deste filme contou com a colaboração técnica da NASA e da IBM para a confeç̧ão do cenário que reproduzia a última palavra na tecnologia disponivel em meados da década de 60 . Um outro filme fornece um bom exemplo para ilustrar a sensibilidade com que a "sétima arte" reflete os mais finos problemas sociais. Trata-se de "Investigações Sobre um Cidadão Acima de Qualquer Suspeita”, de Elio Petri (1970). Nessa história um alto funcionário da polícia romana resolve assassinar deliberadamente sua amante, conservando-se impune. Com o auxilio de computadores, o personagem faz com que as suspeitas recaiam sobre um jovem a cujo respeito a polícia recolhia informações desde 1968 . Esse jovem, sem antecedentes criminais, mas que "professava opinioes trotskistas" tinha toda sua vida recolhida à memória dos computadores da polícia: informações sobre ele colhidas com ou sem o seu consentimento, pois cobriam desde dados de identificação (nome, idade, lugar de nascimento, etc.) a informações sobre suas amizades, fotos tiradas em manifestações públicas, etc. Ele é tomado como símbolo das forças sociais capazes de ameaçar a lei e o Estado e portanto passíveis de controle e sanção. Este filme, ambientado na central de polícia italiana, cujos serviços são inteiramente automatizados, faz uma análise do poder representado tanto pela instituição focalizada como pelo personagem central. É muito significativa a sua fala final, quando, para justificar seu crime, ele diz que está neurótico por causa do poder que concentra em suas mãos e que poderse-ia considerar seu caso como se fosse uma espécie de 
doença profissional. Distribuído no Brasil em 1984, o filme norte-americano "Jogos de Guerra" focaliza a fragilidade dos sistemas de segurança dos computadores e as possibilidades de "crimes eletrônicos", na medida em que o jovem personagem consegue penetrar no Programa de Guerra do Pentágono, através de um contato de seu pequeno computador pessoal com o "WOPR" (War Operation Plan Response). A trama é verossímil, pois a ligação é feita através das linhas públicas - como as telefônicas - utilizadas em todo o mundo para garantir o acesso eletrônico dos usuários de redes de dados. Verossímil ainda que improvável, já que para aceder a bancos de dados de segurança seria preciso a conjugação de inúmeros outros fatores além dos apresentados nessa obra de ficção. Mesmo assim, algumas ocorrências do mesmo tipo relatadas pela imprensa são dignas de nota:

- jovens californianos, a exemplo do personagem do filme, usaram computadores para invadir os arquivos escolares, a fim de alterar suas notas (Jornal do Brasil, 09/01/84);

- um engenheiro de uma indústria paulista de "micros", ao testar o acesso do equipamento a uma rede pública, acabou assumindo o controle da rede (Jornal do Brasil, 28/01/85).

Vale lembrar, por outro lado, que os computadores que controlam os sistemas de defesa dificilmente estarão ligados às congestionadas redes telefônicas, mas sempre operam com linhas especiais. É o caso do Brasil, onde os grandes sistemas de computação se utilizam das Linhas Privadas para Transmissão de Dados, que são linhas especiais. É através delas, por exemplo, que operam os bancos, que dispõem de um computador central e de uma rede de minicomputadores instalados nas agências. Não é fácil ter acesso à linha e aos códigos necessários para permitir a transferência de dinheiro de uma conta para outra, embora este tipo de fraude já tenha ocorrido: em março de 1983, na Holanda, o diretor de um banco de Rotterdam, auxiliado pelo computador da empresa, usou o código que orientava as operaçôes de câmbio para transferir para sua conta pessoal fundos equivalentes a alguns milhões de florins (Jornal do Brasil, 09/01/84).

A fraude eletrônica não deixa rastros, e não existem estatísticas sobre ela porque $95 \%$ dos casos não são descobertos e os restantes $5 \%$ nem sempre vêm a público, pois as empresas raramente desejam prejudicar suas imagens (Isto $E$, $30 / 11 / 83$ ). 0 crime mais comum nos centros de processamento de dados é o roubo de cadastros de clientes, mercado rentável e florescente porque não é dado a nenhuma empresa provar a posse de um cadastro utilizado por outra firma. Este assunto remete ao tema da transferência ilegal de cadastros contendo dados pessoais de país para país, conhecido nos meios especializados como o fenômeno de "Trans- 
border Data Flows". Para lutar contra os crimes e fraudes eletrônicos, lança-se mão dos sistemas de auditoria, sistemas de segurança por voz, calor, etc., e sobretudo da criptografia.

Também dados corretos na origem, mas que passam por codificaçōes intermediárias e consolidaçōes posteriores, estão sujeitos a erros que podem vir a ter conseqüências graves. $O$ que ocorreu, para citar um exemplo, em Düsseldorf, na República Federal da Alemanha, a uma mulher que, ao tomar conhecimento de que sofria de sífilis, entrou em estado de desespero, matando um de seus filhos, tentando matar o segundo e a si mesma. Posteriormente se soube que a informação era falsa, tratando-se de um erro do computador de sua companhia de seguros (Jornal do Brasil, $9 / 11 / 84)$.

Outro filme, apresentado no Brasil em 1983, merece destaque pela tecnologia utilizada. Trata-se de "TRON", produzido pelos estúdios Walt Disney. Neste filme são utilizadas as técnicas de desenho por computador, possiveis a partir de descobertas feitas pelos analistas de sistemas ao trabalharem com gráficos em alta resolução. As técnicas de "CAD" (Desenho Assistido por Computador) possibilitaram a produção de objetos "tridimensionais" e a criação de maravilhosos efeitos visuais. Aí se exemplificam as melhores possibilidades dos recursos tecnológicos para o desenvolvimento da criatividade, inclusive no campo das artes plásticas. Em cinema, deve-se lembrar, finalmente, o clássico filme realizado por François Truffaut "Farenheit $431^{\circ}$ ", ambientado numa sociedade onde o controle social se tornou asfixiante e baseado obviamente no livro de George Orwell, 1984.

Televisão 0 lugar que a televisão ocupa nesse mesmo processo ainda carece de mais estudos e melhor avaliação, sobretudo em nosso país, onde sua importância é crescente há três décadas. Sobre este assunto vale citar, a título de exemplo, um fato noticiado em matéria de página inteira pelo Jornal do Brasil de 12/08/80, tratando de algumas localidades situadas no vale do São Francisco, onde os aparelhos de televisão foram introduzidos a partir de 1956. Com a venda das emissoras dos Diários Associados, a estação transmissora para aquela área interrompeu suas emissões. Subitamente os habitantes daqueles lugares descobriram que já não se ia ao cinema, nem se faziam visitas aos amigos à tardinha e à noite, o footing e os namoros eram prejudicados, os violeiros e cantadores populares que antes eram por ali numerosos haviam abandonado a região. Tudo isso, que são partes de relações sociais e de instituições locais, havia sido trocado pelo vídeo. 
A disseminação indiscriminada de inovações tecnológicas pode, assim, levar à alteração de valores culturais regionais e da própria composição das comunidades, destruindo tecidos sociais muitas vezes insubstituiveis e raramente quantificáveis.

O tema da informatização da sociedade suscita o da identidade humana, pelo uso nem sempre criterioso de inovações em setores suscetíveis de reforçar tendências à desumanização social. A este propósito cabe lembrar o que diz a $\mathrm{UNESCO}^{7}$ :

"A utilização de novas técnicas na administração pode levar à perda de controle dos assuntos públicos por parte das pessoas e ameaçar os direitos politicos e o trabalho".

Assim, a incorporação dos computadores ao trabalho pode contribuir para agravar esse fator de empobrecimento progressivo do ser humano que é o processo de desqualificação profissional. É significativo, por exemplo, o aumento da perda da autonomia sobre o controle do processo de trabatho de que ainda dispõem muitos profissionais. Geralmente, invocando-se o argumento da produtividade, logra-se transferir para o controle de aparelhos eletrônicos todos os atos livres do trabalhador. Esta é certamente a continuação de um longo processo iniciado com a Revolução Industrial ${ }^{1}$.

Por outro lado, a introdução em ambientes de trabalho de aparelhos como os computadores IBM 3750, máquinas de vastos recursos, capazes de controlar linhas telefônicas, conversas particulares, pausas e deslocamentos de empregados nas firmas, suas opiniões políticas e filiação partidária e sindical, tem sido freqüente nos países mais desenvolvidos, e nada impede que o seja também aqui. Parece lícito considerar que instrumentos deste tipo se destinam principalmente a vigiar e têm por finalidade básica o controle político e ideológico do trabalho e do trabalhador.

Deste modo, o uso de inovaçбes tecnológicas pode contribuir para reforçar consideravelmente os sistemas de controle social. Entre esses sistemas, merece destaque o utilizado pelo aparelho de saúde do Estado.

Dois projetos cogitados pelos serviços previdenciários franceses fornecem indicações interessantes a este propósito. Trata-se dos projetos "Gamin" (Gestion Automatisée de la Médécine Infantile) e "Audass" (Automatisation des Directions Departementales d'Action Sanitaire et Sociale). $O$ primeiro se destinava a manter um arquivo contendo informaçбes médicas e não-médicas sobre os recém-nascidos e seus pais, com o objetivo de identificar quais as crianças que ao nascer representam "riscos" políticos e sociais para a comunidade, futuramente. $O$ segundo tratava de recolher os dossiers de todas as pessoas que já tivessem recorrido alguma vez à Assistência Social, para identificar os desvian-
Controle e Trabalho

Controle e Saúde 
*Quando a NASA lançou a nave espacial Columbia, em novembro de 1980 , a imprensa noticiou os esforços significativos, porém mal sucedidos, dos cientistas norte. americanos que desejavam ampliar os objetivos cientificos da missão, prejudicados pelos interesses militares.

Controle e Comportamento Cívico tes em relação aos parâmetros de normalidade e adaptabilidade social ${ }^{5}$. Os nomes desses projetos remetem às palavras: Gamin = guri e Audass = audácia e fornecem um código suplementar de leitura, bem ao gosto francês pelo jogo de palavras, chamando a atenção para os seus múltiplos significados. Assim, também, a palavra que os franceses escolheram para designar o computador é, do ponto de vista do controle social, a mais exata de quantas são utilizadas: "ordinateur", isto é, aquele que põe ordem, que ordena.

Ainda que esses projetos não tenham sido concluídos, a sua simples cogitação sugere 0 alcance de suas possibilidades. Eles indicam ainda que a medicina que disciplinou e higienizou a sociedade burguesa ocidental desde fins do século XVIII, colaborando intimamente para o sucesso da Revolução Industrial e a consolidação do capitalismo, pode, com o auxilio dos recursos trazidos pela informática, ampliar e sofisticar um aparelho de esquadrinhamento social em cujo cerne a política psiquiátrica poderia exercer um papel fundamental. $O$ fato, por exemplo, de se manter em fichas clínicas o registro da passagem por serviços psiquiátricos é capaz de prejudicar, e certamente o tem feito, o acesso ao trabalho.

Outra conseqüência a ser lembrada, esta ao nível do comportamento, é a passividade. Os instrumentos tecnológicos encontram aplicação em vastos campos da atividade social, incluindo-se aí a guerra.*

Eles são particularmente adequados à coerção: controle realizado pela espionagem, chantagem, controle político, do trabalho, médico, psiquiátrico, asilar, policial e até do lazer e do consumo. A lista é aparentemente inesgotável, assim como o é a relação de instrumentos disponíveis.

Nos nossos dias, todos os acontecimentos políticos estão cercados de sofisticados recursos tecnológicos destinados ao controle. No dia 17 de julho de 1980, para citar um exemplo reportado pela imprensa, o Jornal do Brasil publicou uma matéria de página inteira sobre a Convenção do Partido Republicano dos Estados Unidos da América do Norte que ratificava a indicação do seu candidato às eleições presidenciais daquele país. Numa coluna de canto de página, podiase ler a seguinte notícia breve: "Azar foi o de Calvin Leroy Hall, 21 anos, cozinheiro de um restaurante, que está prestando serviços à Convenção. Como parte da rotina, seu nome foi enviado pelo Serviço Secreto ao computador do Centro Nacional de Informações Criminais. Os arquivos implacáveis indicaram que ele era procurado por assassinato em Ohio e estava foragido há dois anos. Já foi extraditado e está preso". Vale a pena destacar nesta pequena notícia dois aspectos: primeiro, que "faz parte da rotina" esquadrinhar a vida de todas as pessoas que estarão envolvidas direta ou in- 
diretamente num evento político. Essa expressão facilita ao aparelho de control a desdramatização de suas atividades, fazendo com que a repressão e a vigilância pareçam atividades normais. Em segundo lugar, a referência expressa aos arquivos secretos mantidos pelo aparelho político-policial do Estado. Somente as legislações da Suécia e da Noruega incluem o direito de notificação (sem os de consulta e alteração) das informaçð̄es estocadas nesses arquivos.

Desta forma, a sensação de impotência face aos recursos tecnológicos pode provocar medo e apatia política, resulta. do certamente indesejável para qualquer sociedade que pretenda alcançar a democracia.

Os governos de vários países vêm se preocupando com essas questōes. Por outro lado, a imprensa e os grupos de pressão há tempos se manifestam sobre esses assuntos. Nos Estados Unidos da América do Norte, na França, na GrãBretanha e na República Federal da Alemanha, entre ou. tros, já há projetos de lei em vigor ou em cogitação, visando proteger ao máximo os cidadãos e as liberdades civis. $O$ caso dos países escandinavos, notadamente o da Suécia que possui a legislação mais cuidadosa e flexível sobre tais assuntos, é exemplar. Neste país, toda uma legislação específica, abrangendo diferentes aspectos da privacidade, dos bancos de dados, da segurança e confiabilidade dos dados processados eletronicamente foi incluída na Constituição. Contudo, mesmo lá permanecem contradiçðes entre o direito de verificação e correção dos dados pessoais (Suécia, Noruega) e a existência de arquivos inacessíveis. Do mesmo modo, o fato de que algumas garantias sejam fornecidas às pessoas não impedirá que elas sejam fichadas. Na França, por exemplo, uma sociedade considerada liberal, o governo condena mas não proíbe o cadastramento de militantes políticos e sindicais.

\section{OBSERVAÇÕES FINAIS}

O Brasil está entre os países em deserivolvimento desfavorecidos por uma situação de dependência tecnológica, na medida em que se industrializaram pelo processo de substituição de importaçбes e dentro do sistema da divisão internacional do trabalho.

Os prejuízos causados ao país pela importação de tecnologia são grandes. Assim também a falta de um planejamento mais cuidadoso, voltado para os brasileiros, coloca nosso pais em posição delicada face aos efeitos societais da informática.

Os valores culturais regionais e a própria composição sócio-cultural das comunidades têm sido profundamente atingidos e modificados. Sobre a parte de tais mudanças que cabe à televisão, já se mencionou um exemplo. É possível 
Dependência Tecnológica

* A questão do desemprego tecnológico, um dos efeitos mais importantes da automatização, merece atenção especial. $O$ tratamento aprofundado com que deve ser abordada não cabe infelizmente neste artigo, cujos propósitos são gerais. arrolar-se outros. Assim, a festa tradicional de São Gonçalo, que atrai anualmente a Cuiabá milhares de pessoas, também foi alterada para que o evento não atrapalhasse a audiência dos telejornais e telenovelas.

Destacam-se, ainda, quanto à televisão os efeitos de passividade e indução que sua difusão provoca, principalmente sobre as crianças. Importa lembrar, novamente, o seu poder de destruição sobre frágeis tecidos sociais, como os relacionamentos interpessoais, as festas e as tradiçues populares que constituem a trama cultural de comunidades inteiras.

$\mathrm{O}$ advento da informática provocou um remanejamento no equilíbrio de poder mundial. Às nações ricas interessa, hoje, promover a industrialização dos países em desenvolvimento com tecnologia importada, de modo a viabilizar seu avanço como sociedades pós-industriais, criando e exportando para o resto do mundo a "inteligência" e o conhecimento para a produção. A indústria brasileira ainda não se robotizou completamente, porém o Brasil importa máquinas-ferramentas destinadas à indústria, sobretudo a automobilística. Tais máquinas, geralmente operadas por computador, como é o caso das grandes prensas industriais, são um fator de desemprego imediato de mão-de-obra especializada *.

Por outro lado, o exame da questão da autonomia tecnológica indica que, subjacente aos argumentos da racionalidade, existe um modelo civilizatório que vai sendo transferido paulatinamente dos países centrais para os periféricos, independentemente das necessidades de cada um. A importação de tecnologia viabiliza, ainda, a introdução e difusão de modelos culturais estrangeiros. Categorias como o raciocínio lógico e a linguagem uniformizada, inerentes ao computador, apresentam inconvenientes quando disseminadas sem planejamento - por exemplo, para a educação. Ainda porque os aparelhos tecnológicos têm uma via de penetração imediata e benevolente nas crianças que interagem com os computadores com facilidade: nas Feiras de Informática, montadas anualmente no Rio de Janeiro e em São Paulo, o contingente de crianças e adolescentes que visitam os stands, atraídos pelos numerosos jogos, programas escolares informatizados e "xerox" coloridos, é mais do que expressivo. Os jogos eletrônicos, denominados comumente de "videojogos" e "fliperamas", são um estímulo à aproximação entre o ser humano e as novas máquinas. Diversão juvenil, eles foram transpostos das telas de TV para os terminais de vídeo, gerando um resultado notável entre as crianças que adquirem grande facilidade e destreza em manusear os computadores, cada vez mais entrosadas que estão com os sofisticados brinquedos eletrônicos. Por serem obsessivos, não são menos fascinantes e chegam a permitir, desde que 
ligados a computadores, a elaboração tanto de deveres de casa como de gráficos tridimensionais e mesmo a composição de música eletrônica.

Por outro lado, não só as máquinas, mas principalmente os programas são importados. Tal fato remete novamente à questão da urgência da criação de uma "inteligência para produção brasileira nos meios de produção brasileiros e, em particular, de uma tecnologia genuinamente brasileira, aqui criada e voltada para as nossas necessidades" 4 .

Nos últimos anos foi possível acompanhar através dos meios de comunicação o grande debate travado entre o Governo Brasileiro, representado pela Secretaria Especial de Informática, de um lado, e os produtores brasileiros de computadores e componentes eletrônicos de outro. Um último parceiro nessa contenda eram as companhias multinacionais. $\mathrm{O}$ embate se travava em torno da reserva de mercado, questão crucial no momento em que se tenta implantar uma indústria de aparelhos eletrônicos no país. Resultou disso tudo uma lei sancionada em meados de 1984, pelo Congresso Nacional, em que se contemplou a reserva técnica mínima in dispensável. Diversos parlamentares tentaram incluir nesse documento dispositivos visando à proteção da privacidade e das garantias individuais. Infelizmente tais dispositivos não foram aprovados nessa ocasião.

Entre nós, continuam, portanto, atuais todas as perguntas sobre que tipo de garantias serão dadas aos cidadãos para protegê-los dos inevitáveis abusos. No caso do Brasil, todas as dúvidas levantadas mundialmente sobre o número único, a privacidade e a introdução maciça e descontrolada de recursos tecnológicos permanecem de obrigatória oportunidade.

Concluindo pois que a informatização da sociedade brasileira é um processo inevitável, que grandes sistemas de informações já em montagem serão consolidados em breve e outros serão construídos, seria in teressante que o processo passasse pelo crivo de mecanismos, inclusive jurídicos, capazes de detectar os inconvenientes, avaliá-los e reagir no mesmo ritmo em que as inovações tecnológicas forem implantadas.

Vale lembrar que a informática tem igualmente incontáveis aplicações benéficas. Para a pesquisa, serviços meteorológicos, controle de tráfego ferroviário, aéreo e urbano, organização de museus e bibliotecas, restauração de obras de arte, sem falar na amenização de trabalhos penosos e na eliminação de muitas tarefas cansativas - a lista dos benefícios sociais também é muito extensa. Portanto, não se trata de ser contra a informatização social, ain da porque não é uma questão de engenharia que se discute, mas sim o desgoverno de mudanças que podem levar a resultados indese- 
jáveis. Não é, pois, o caso de renunciar ao progresso técnico, mas sim de lutar contra a premissa de que a modernidade é sinônimo de repressão e controle e procurar criar alternativas para o destino trágico de um panóptico eletrônico.

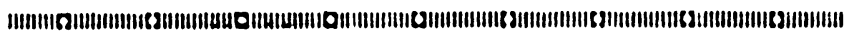

Os processos automáticos que se vão implantando em praticamente todos os paises do mundo neste final de século provocam impactos em áreas sociais, assim como sobre uma série de valores culturais. Neste artigo procura-se fazer um balanço geral dessas modificą̧ões.

\section{REFEREANCIAS BIBLIOGRÁFICAS}

1. BRAVERMAN, Harry. Trabalho e capital monopolista. Rio de Janeiro, Zahar, 1974.

2. Debate on Information Privacy, part 1. EDP Analyser, 13 (11) :4, 1975.

3. LABORIT, Henri. La societé informationnelle. Paris, Les Editions du Cerf, 1973.

4. MARQUES, Ivan Costa. Uma etapa histórica desmentida. Dados e idéias, 1 (6) :48.56, 1976.

5. OLIVEIRA, Maria Teresa de. A privacidade ameaçada. Dados e idéias, 2 (5):69.81, 1977.

6. TAVARES, Cristina. Projeto de lei no 2796B, sobre o acesso às informações pessoais, Brasilia, Câmara dos Deputados, 1980.

7. UNESCO. Intergovernmental Bureau of Informatics. Consideraciones sobre las repercusiones sociales de la informática. Roma, 1976. 